NBER WORKING PAPER SERIES

\title{
INTEGRATION OF UNEMPLOYMENT INSURANCE WITH RETIREMENT INSURANCE
}

\author{
Joseph Stiglitz \\ Jungyoll Yun \\ Working Paper 9199 \\ http://www.nber.org/papers/w9199 \\ NATIONAL BUREAU OF ECONOMIC RESEARCH \\ 1050 Massachusetts Avenue \\ Cambridge, MA 02138 \\ September 2002
}

The views expressed herein are those of the authors and not necessarily those of the National Bureau of Economic Research.

(C) 2002 by Joseph Stiglitz and Jungyoll Yun. All rights reserved. Short sections of text, not to exceed two paragraphs, may be quoted without explicit permission provided that full credit, including (C notice, is given to the source. 
Integration of Unemployment Insurance with Retirement Insurance Joseph Stiglitz and Jungyoll Yun

NBER Working Paper No. 9199

September 2002

\begin{abstract}
$\underline{\text { ABSTRACT }}$
This paper analyzes a social insurance system that integrates unemployment insurance with a pension program through an individual account, allowing workers to borrow against their future wage income to finance consumption during an unemployment episode and thus improving their search incentives while reducing risks. This paper identifies factors which determine the optimal degree of integration. A fully integrated system is one in which no reliance is placed at all on a separate tax-funded unemployment insurance program. We show that when the duration of unemployment is very short compared to the period of employment or retirement, the optimal system involves an exclusive reliance on pension-funded self-insurance. This system imposes a negligible risk burden for workers while avoiding attenuating search incentives. We also argue that a joint integration of several social insurance programs with a pension program through an individual account is desirable unless the risks are perfectly correlated to each other.
\end{abstract}

Joseph Stiglitz

Institute for International Studies

Encina Hall C100

Stanford University

Stanford, CA 94305

and NBER

stiglitz@stanford.edu 


\section{Introduction}

The East Asian crisis brought home to much of the developing world a lesson that the Great Depression brought home to more advanced countries seventy years ago- the importance of a safety net. But as countries like Korea go about constructing their safety nets, they are cognizant of the complaints that have been raised against unemployment insurance systems: they attenuate incentives. To be sure, there are adverse incentive effects (or, as they are today generally referred to, moral hazard effects) in all insurance programs. What worries critics is that the risk reduction benefits might, on the face of it, be outweighed by the adverse incentive effects. For most individuals, a typical spell of unemployment is less than six months (and that spell would presumably be shorter, possibly much shorter in the absence of unemployment insurance.) Over a working time of, say, forty-five years, an individual with three such spells would lose perhaps $4 \%$ of his lifetime income - a risk which presumably the individual could easily absorb if he had sufficient savings or could borrow against future earnings. With the bulk of savings used for retirement, and mostly dedicated to social security programs, the amount individuals have to buffer themselves against these income shocks is limited; and well documented limitations in capital markets make it difficult for individuals to borrow much against future earnings. Thus compulsory old age public pension programs, while they help resolve one problem - the tendency of individuals not to save enough for their old age, because of the proclivity of public "bail-outs"- exacerbate another.

This naturally leads to the suggestion of an integrated unemployment and pension program, which we will call the integrated unemployment insurance (UI) system. Such 
integration makes particular sense with individual accounts, which are increasingly forming the basis of even public pension programs. ${ }^{1}$ In such programs, benefits are related to contributions by simple formulae; in the simplest form, there is no redistribution. Such programs are like defined contribution pension programs, though some of the contributions can be used to "purchase" insurance (e.g. against inflation or interest rate fluctuations) which is not available on the market. But it is easy to impose redistributions on top. For simplicity, in this paper, we will ignore the redistributive components. $^{2}$

Under the integrated UI system through an individual account, an individual who is unemployed can have his unemployment payments taken out of his individual account. Thus, the individual obtains the liquidity to maintain his standard of living; the compulsory and universal nature of the contributions provide, in effect, perfect collateral, so that early on in his life, his account balance could become negative. The fact that normally the risk is small means that the individual can bear this risk-when it is spread out over his entire life; and since the individual bears the risk, there is no attenuation of job search incentives.

If, however, the loss from unemployment is large enough, it is optimal to have some true unemployment insurance - the individual should not bear the cost even over his lifetime. In general, individuals should not rely exclusively on the pension-funded selfinsurance under the integrated UI system. In this paper we take this 'lifetime' unemployment insurance to be tax-funded, but the results would be identical with a mandatory private insurance program with competitively determined premia. ${ }^{3}$ Taking this into account, we characterize in this paper the optimal benefit structure of the integrated 
UI system, that is, the optimal combination of the two types of benefits - tax-funded and pension-funded. The lower the risk-aversion, or the greater the elasticity of search with respect to the insurance benefit, the less reliance should be placed on tax-funded insurance as opposed to (what might be viewed as implicit) pension-funded selfinsurance. In an extreme case, if a worker is risk-neutral, then there should be no need for tax-funded unemployment insurance, and if there is no incentive problem associated with unemployment insurance, there is no need to rely on pension-funded self-insurance. Not surprisingly, the larger the risk, which in turn is related to the length of the period of unemployment relative to the working period, the greater the need for tax-funded insurance. In the limit, if the period of unemployment is vanishingly minute, then the individual can bear all the risk through pension-funded self-insurance with no welfare loss.

Unemployment is, of course, only one of many risks that individuals face. There are, for instance, the risks of disability and health, as well as unemployment. The idea of integration can be applied to each of these risks, leading us to consider what we call an integrated lifetime insurance program. Under the integrated lifetime insurance pension savings can be used to provide cover for these risks. The Provident Funds of Malaysia and Singapore provide prototypes of such an integrated program. The problem is that while the loss from any one of these risks may be small, there is some chance the individual may experience all of these losses. In that case, the funds available to an individual at the time of retirement may be reduced to an unacceptably low level .If the government has to provide lifetime insurance to cover such contingencies - in effect, bailing out the individual account because it would provide an unacceptably low level of 
pension, the borrowing by an individual to smooth consumption to cover any one of these risks would have an adverse disincentive effect much as the tax-funded benefit does. These considerations might appear to diminish the relevance of joint integration.

We argue in this paper, however, that so long as the risks are not perfectly correlated then it always pays to integrate all the social insurance programs with the pension program rather than to have separate insurance programs covering each risk. The key point is that the integrated lifetime insurance system allows a given amount of pension savings of an individual to be used for the benefits under all the risks. This benefit of joint integration—having a common pool from which to draw upon—gets larger as the correlation gets smaller.

In the next section we present a basic model for an integrated UI system to characterize its optimal benefit structure and to show how it varies with the relative size of unemployment risk and other parameters. Section 3 provides an informal presentation for an integrated lifetime insurance system to argue for its optimality. Some concluding remarks are given in Section 4.

\section{The Model}

Consider an infinitely-lived worker who spends $(\mathrm{M}+2)$ periods working and retires for the remaining $\mathrm{N}$ periods, as depicted in Figure 0 . In period 2 a worker becomes unemployed with probability q. The length of unemployment depends upon his search decision. In this paper we assume that a worker can choose either 'no search' or 'search'. If he searches, he gets reemployed immediately after the unemployment shock. If he does 
not search, he remains unemployed for one period. Thus, depending upon his search decision, a worker with an unemployment shock can either be employed or unemployed in period 2. The cost of search e is a random variable, which is distributed with distribution function $\mathrm{F}(\mathrm{e})$. There is a threshold search cost $\mathrm{e}^{\prime}$, such that he chooses to search (or not to search) if $\mathrm{e}<\left(\right.$ or $>$ ) $\mathrm{e}^{\prime}$. Thus the probability of being unemployed in period 2 is $\mathrm{q}\left(1-\mathrm{F}\left(\mathrm{e}^{\prime}\right)\right)$.

Suppose there is a public pension program, ${ }^{4}$ to which an individual worker is mandated to contribute a certain portion of his income. Although it does not matter whether the pension program is of a defined-contribution or of a defined-benefit type, here we will assume for simplicity that an individual's pension is determined simply by his contributions. In addition to mandatory savings, an individual may also have voluntary private savings for retirement or to cover the risk of unemployment in the future.

Under the integrated UI system, the unemployment benefit comes from two sources: from a formal unemployment program, funded by an unemployment insurance tax, and from the past and prospective mandated pension savings. If the period of unemployment is small enough and/or the mandated level of savings is high enough, and if the individual is allowed to borrow as much as he wants from his individual account, there would be no additional precautionary savings to cover the risk of unemployment. . In other words, an individual would save just for retirement.

The main objective of the integrated UI system is to provide efficient consumption smoothing and lifetime risk absorption, while minimizing the adverse search incentives. We approach the problem in several stages. We first pretend the government could control perfectly consumption at every date in every state and circumstance (that is, 
whether the individual does or does not face an unemployment shock) as well as search (which will presumably depend on the cost of search e) to characterize the first-best optimum. We then analyze the constrained optimum, where the government cannot directly control whether individuals search the government knows however, that their search decisions will depend on the benefits provided. We next characterize a set of unemployment insurance tax and benefits as well as mandated savings and retirement benefits the government needs to achieve this constrained optimum, examining, in particular the factors that determine the optimal degree of integration. In doing this we will assume for the expositional simplicity that there is no discounting for money and utility. This will enable us to identify more clearly the welfare gains associated with the integrated UI system.

Let $C_{1}$ be the consumption in period 1 for an individual. From period 2 on, there are two different work-states possible for an individual: 'unemployed in period 2' (U) and 'employed in period 2' $(\mathrm{N})$. A worker with one work-state chooses his consumption pattern over time differently from the one with the other work-state.

Let $C_{n, t}, C_{u, t}$ (for $\mathrm{t}>1$ ) be the amount of consumption at time $\mathrm{t}$ for an individual with work-state $\mathrm{N}, \mathrm{U}$, respectively. Then, assuming that consumption $\mathrm{C}$ and search effort $e$ are separable in the utility function, we can represent his expected utility as follows:

$$
\begin{aligned}
V\left(C_{1}, C_{n, t}, C_{u, t}, q\right) & =U\left(C_{1}\right)+\left(1-q\left(1-F\left(e^{\prime}\right)\right)\right) \sum_{t=2}^{M+N+2} U\left(C_{n, t}\right)+q\left(1-F\left(e^{\prime}\right)\right) \sum_{t=2}^{M+N+2} U\left(C_{u, t}\right) \\
& -q \int_{0}^{e^{\prime}} e d F(e)
\end{aligned}
$$


where $\left\{C_{1}, C_{n, t}, C_{u, t}\right\}_{t}$ satisfies the following constraint:

$$
C_{1}+\left(1-q\left(1-F\left(e^{\prime}\right)\right) \sum_{t=2}^{M+N+2} C_{n, t}+q\left(1-F\left(e^{\prime}\right)\right) \sum_{t=2}^{M+N+2} C_{u, t}=\left(M+2-q\left(1-F\left(e^{\prime}\right)\right) w\right.\right.
$$

The above constraint indicates that the sum of the expected consumption over a lifetime should be equal to the expected lifetime wage income earned. This can also be interpreted as an aggregate constraint based upon the law of large numbers.

\section{First Best Solution}

Maximizing the expected utility function V subject to the above constraint, with

respect to consumption at each date and in work state $\left\{C_{1}, \hat{C}_{n, t}, \hat{C}_{u, t}\right\}$ and with respect to the threshold search cost $\hat{e}$, we have

$$
\begin{array}{r}
\hat{C}_{1}=\hat{C}_{n, t}=\hat{C}_{u, t}=\hat{C}, \\
=\frac{M+2-\hat{q}}{M+2+N} w
\end{array}
$$

for all $\mathrm{t}(>1)$ — there is complete consumption smoothing - and

$$
\hat{e}=U^{\prime}(\hat{C}) w
$$


where $\hat{q} \equiv q(1-F(\hat{e}))$. In our model, search always yields a job, which generates a wage of w and a marginal utility of U'w; it pays to search so long as the cost of search (in utility terms) is less than the cost.

The first-best expected utility $\hat{V}$ of an individual would then be

$$
\hat{V}=(M+2+N) U(\hat{C})-\int_{0}^{\hat{e}} e d F
$$

\section{Second best optimum}

In fact, however, the government cannot directly control individual search behavior. If the government guaranteed consumption irrespective of search, no individual would have an incentive to search. The threshold search cost $\mathrm{e}^{\prime}$ chosen by an individual worker will be the one that maximizes his expected utility $\mathrm{V}$ without taking into account its effect upon the constraint (2). Thus, we have

$$
e^{\prime}=\sum_{t=2}^{M+N+2} U\left(C_{n, t}\right)-\sum_{t=2}^{M+N+2} U\left(C_{u, t}\right)
$$

The optimal outcome that the government can achieve given its inability to control individual search behavior, otherwise called the second-best optimum, can be characterized by maximizing the expected utility $V($.$) subject to the constraint (2) and the$ individual search behavior constraint (3). A detailed analysis of the second-best optimum will be given later in this section, where the optimal benefit structure of the integrated UI 
system is characterized. But one can see that the additional constraint (3) implies that the second-best set of consumptions $\left\{C_{1}{ }^{*}, C_{n, t}^{*}, C_{u, t}^{*}\right\}$ and threshold search cost $e^{*}$ satisfies

$$
\begin{aligned}
C_{n, t}^{*} & =C_{n}{ }^{*}, \\
C_{u, t}^{*} & =C_{u}{ }^{*}
\end{aligned}
$$

for all $\mathrm{t}=2,--, \mathrm{M}+\mathrm{N}+2$, and

$$
\begin{aligned}
& C_{n}^{*}>C_{u}{ }^{*} \\
& C_{n}^{*}>C_{1}^{*}>C_{u}^{*} \\
& e^{*}=(M+N+1)\left\{U\left(C_{n}^{*}\right)-U\left(C_{u}^{*}\right)\right\} .
\end{aligned}
$$

The condition (SB-1) says that, from period 2 on, the consumption in each period should be equal for each work-state $\mathrm{N}$ or $\mathrm{U}$, which is also required for the first-best. The condition (SB-2), however, states that per period consumption for those with work-state U should be less than that for those with work-state N. This is due to the moral hazard associated with a search incentive, and distinguishes the second-best from the first-best.

\section{II.1. The Second-Best Savings, Borrowings and UI Benefits}


To identify a set of savings, borrowings and UI taxes and benefit that generates the second-best consumption pattern for an individual, we will first figure out how those variables determine the consumption level in each period for each state. In this model the UI tax $\mathrm{T}$ is paid only in period $1^{5}$, and the unemployment benefit $\mathrm{B}$ paid in period 2 consists of the benefit $r$ funded by UI tax $\mathrm{T}$ and the benefit $\mathrm{R}$ funded by lifetime savings. The benefit $\mathrm{R}$ is self-insurance for an unemployed worker, which can be financed either by his pre-unemployment private savings or by borrowings from his future pension savings. The distinction between these two is important in this paper, for reasons which will be discussed later.

The condition (SB-1) for consumption smoothing implies that the savings of an individual with a given work-state should be the same for all periods, because in this model a worker faces the same wage for each period while there is no discounting. Let $s_{1}, s_{u}$, and $s_{n}$ be the savings rate in period 1 , the savings rate for those with work-state $\mathrm{U}$ and $\mathrm{N}$, respectively. Then, we have

$$
\begin{aligned}
& C_{1}=w\left(1-s_{1}-T\right) \\
& C_{n, t}=w\left(1-s_{n}\right), \quad t=2,--, M+2 \\
& C_{n, t}=w \frac{(M+1) s_{n}+s_{1}}{N}, \quad t=M+3,--, M+N+2 \\
& C_{u, 2}=w(r+R) \\
& C_{u, t}=w\left(1-s_{u}\right), \quad t=3,--, M+2 \\
& C_{u, t}=w \frac{M s_{u}+s_{1}-R}{N}, \quad t=M+3,--, M+N+2
\end{aligned}
$$

Let $\left\{s_{1}{ }^{*}, s_{n}{ }^{*}, s_{u}{ }^{*} ; r^{*}, R^{*}, T^{*}\right\}$ be a set of the optimal variables that can achieve the secondbest optimum. Then, substituting (4) into the expected utility function V( ) in (1), we can 
solve for these variables by maximizing $\mathrm{V}($.$) subject to the individual search behavior$ constraint (3) and the government budget constraint. More specifically, the variables $\left\{s_{1}{ }^{*},{s_{n}}^{*}, s_{u}{ }^{*} ; r^{*}, R^{*}, T^{*}\right\}$ solve the following optimization problem:



subject to

$$
\begin{array}{ll}
e^{*}=I\left(M, N, s_{1}\right)-J\left(r ; M, N, s_{1}\right) & \text { (Individual Search Constraint) } \\
T=\bar{q} r . & \text { (Government Budget Constraint) }
\end{array}
$$

where

$$
\begin{aligned}
& \bar{q} \equiv q\left(1-F\left(e^{*}\right)\right) \\
& I\left(M, N, s_{1}\right)=M_{s_{n}} a x(M+1) U\left(\left(1-s_{n}\right) w\right)+N U\left\{\frac{(M+1) s_{n}+s_{1}^{*}}{N} w\right\} \\
& J\left(r, R ; M, N, s_{1}\right)=M_{s_{u}, R} U((r+R) w)+M U\left(\left(1-s_{u}\right) w\right)+N U\left(\frac{M s_{u}+s_{1}{ }^{*}-R}{N} w\right)
\end{aligned}
$$

The valuation functions $\mathrm{I}($.$) and \mathrm{J}($.$) measure the payoff as of period 2, depending on$ whether the individual is or is not employed in period 2, respectively. For the purpose of simplicity, we will hereafter normalize the wage at unity. 
Before characterizing the second-best optimum, we will briefly outline the underlying intuitions. In determining the second-best savings, borrowings and UI benefit, the consumption smoothing across periods or across work states is critical. The maximization problems (8) and (9) suggest that the optimal savings and borrowings $\left\{s_{n}{ }^{*}, s_{u}{ }^{*}, R^{*}\right\}$ are to be set solely based upon intertemporal consumption smoothing for those in a given work state $\mathrm{N}$ or $\mathrm{U}$. The optimal savings $\mathrm{s}_{1}{ }^{*}$ in period 1 and the optimal UI benefit $\mathrm{r}^{*}$ (and its tax $\mathrm{T}^{*}$ ) are also affected by consumption smoothing across periods and across work states, respectively. As for $\mathrm{s}_{1}{ }^{*}$ and $\mathrm{r}^{*}$, however, another consideration may also apply. Although an individual takes UI tax $\mathrm{T}$ as given in choosing his search strategy as implied by (6), $\mathrm{T}$ depends upon the unemployment probability $\bar{q}$, which is in turn affected by an individual search decision. In determining $\mathrm{s}_{1}{ }^{*}$ and $\mathrm{r}^{*}$, therefore, we have to take into account their effects upon $\mathrm{T}$. In other words, $\mathrm{s}_{1}{ }^{*}$ and $\mathrm{r}^{*}$ will be set to facilitate consumption smoothing across periods and work states, taking incentive effects into account. Differentiation of (6) with respect to $r$ and $s_{1}$ will provide us with the following results about their effects upon individuals' search decision:

\section{Lemma}

(i) $\frac{\partial e^{*}}{\partial r}=-U^{\prime}\left(\frac{M+r+s_{1}}{N+M+1}\right)<0$.

(ii) $\frac{\partial e^{*}}{\partial s_{1}}=\left\{U^{\prime}\left(\frac{M+1+s_{1}}{N+M+1}\right)-U^{\prime}\left(\frac{M+r+s_{1}}{N+M+1}\right)\right\}<0$. 
The proof of the Lemma can be found in the Appendix. Lemma (i) shows that an individual worker's search decision is adversely affected by the tax-funded UI benefit $r$. This is the source of well-known welfare cost associated with the UI system. Lemma (ii) shows that the savings in period 1 would also negatively affect search effort decision, because a worker with greater private savings would not take as serious the reduction in his account balance. In other words, an individual search decision is negatively related to one's post-unemployment lifetime consumption. To the extent that savings in period 1 is only a small portion of one's post-unemployment lifetime consumption, therefore, its effect on $\mathrm{e}^{\prime}$ would also be minimal. In particular, we will assume that $\mathrm{q}$ is so small relative to $\mathrm{M}$ and $\mathrm{N}$ that

$$
\frac{q}{N+M} \approx 0
$$

Under the assumption (A) the effect of $\mathrm{s}_{1}$ upon UI tax T would become negligible, because, by Lemma (ii),

$$
\frac{\partial T}{\partial e^{\prime}} \frac{\partial e^{\prime}}{\partial s_{1}} \approx 0
$$

where $\frac{\partial T}{\partial e^{\prime}}=q f\left(e^{\prime}\right) r_{1}$ by (7). Since the assumption (A) enables us to ignore the search incentive effect of $\mathrm{s}_{1}$ in determining its optimal value, the optimal savings $\mathrm{s}_{1}{ }^{*}$ in period 1 will be determined only by consumption smoothing across periods in the model. ${ }^{6}$ 
Let $a \equiv \frac{M+2}{N}$ be the ratio of length of working career to retirement duration. Then, we can establish the following Proposition on the second-best set of savings, borrowings and UI benefit.

\section{Proposition 1}

(i) $s_{1}{ }^{*}+T^{*}=\frac{1}{1+a}$, where $T^{*}=\bar{q} r^{*}$,

(ii) $1-s_{n}^{*}=\frac{M+1+\frac{1}{1+a}}{N+M+1}$

(iii) $1-{s_{u}}^{*}=\frac{M+1+\frac{1}{1+a}}{N+M+1}-X^{*}$, where $X^{*}=\frac{1-r^{*}}{N+M+1}$,

(iv) $R^{*}=\frac{M+1+\frac{1}{1+a}}{N+M+1}-X^{*}-r^{*}$.

(v) $\left.\delta X^{*}-U^{\prime}\left(\frac{a}{1+a}\right)\right) H r^{*}=0$, where $H \equiv \frac{f(.)}{1-F(.)}, \delta \equiv-\frac{U^{\prime \prime}}{U^{\prime}}$.

Proposition 1 suggests that the second-best savings, borrowings and UI benefit can be characterized as a function of exogenous parameters, $H, \delta, M, N, q$. Here $\delta$ represents an Arrow-Pratt measure of absolute risk aversion and $H$ indicates search elasticity or the sensitiveness of reemployment probability to the increase in threshold search cost $e^{\prime} .7$

Rewriting (i) as $1-s_{1}{ }^{*}-T^{*}=\frac{a}{1+a}=\frac{M+2}{N+M+2}$, we can see that the optimal savings $\mathrm{s}_{1}{ }^{*}$ 
in period 1 is determined as a retirement savings based on intertemporal consumption smoothing for given $\mathrm{r}^{*}$, not as a precautionary savings against unemployment risk. Without the government provision of pension-funded borrowing, however, the savings $\mathrm{s}_{1}$ in period 1 would also have to serve as a precautionary savings against unemployment shock. This is the case for the conventional UI system, which will be discussed later. By (ii) and (iii) the optimal savings after period 1 are also to be determined solely by intertemporal consumption smoothing for given UI benefit $\mathrm{r}^{*}$.

As for the second-best self-insurance $\mathrm{R}^{*}$ (using pension savings), it is also determined by intertemporal consumption smoothing as shown in (iv). Although the government provides an unemployed worker with tax-funded benefit $\mathrm{r}^{*}$, it may be short of his optimal consumption level, due to the concern about search incentives. Given the limitation of the tax-funded benefit $\mathrm{r}^{*}$, an unemployed worker may rely on a certain amount $\mathrm{R}^{*}$ of pension-funded self-insurance that supplements $\mathrm{r}^{*}$. $^{8}$

On the other hand, the optimal UI benefit is set by (v) to balance consumption smoothing between the two work states $\mathrm{N}$ and $\mathrm{U}, .$, (which represents the provision of insurance) with the concern about incentives. The first term $\delta X^{*}$ of (v) reflects the marginal insurance benefit provided by $\mathrm{r}$, while the second term $\left.U^{\prime}(a)\right) H r^{*}$ represents its marginal incentive cost.

Note that the marginal insurance benefit of $\mathrm{r}$ is positively related to $X$, the amount of consumption reduction per period due to unemployment. This implies that the risk burden that an individual has to bear due to the limitation of $r$ depends upon the amount of consumption reduction per period, not upon the total consumption reduction. The amount of total (lifetime) consumption reduction due to unemployment is (1-r). If an 
unemployed individual would not be able to borrow, therefore, the risk burden of unemployment he has to bear would be positively related to (1-r). Under the integrated UI system in which an individual can borrow, however, he can spread out the reduction in lifetime income over the working and retirement period. This reduces the risk burden associated with the incomplete provision of insurance against unemployment . This is how integrated UI system improves the trade-off between insurance and incentive, thereby enhancing welfare.

Taking into account the fact that the optimal self-insurance $\mathrm{R}^{*}$ and tax-funded UI benefit $r^{*}$ are partial substitutes for each other(by (iv) of Proposition 1), the relatively small marginal insurance benefit of $r$ under the integrated UI suggests a smaller taxfunded UI benefit under the integrated system. Some of the tax-funded UI benefit is replaced by self-insurance. A complete set of comparative statics about the mix of selfinsurance and tax-financed insurance is presented in the following Proposition.

\section{Proposition 2}
(i) $\frac{\partial r^{*}}{\partial H}<0, \frac{\partial R^{*}}{\partial H}>0, \frac{\partial B^{*}}{\partial H}<0$, where $B^{*}=r^{*}+R^{*}$
(ii) $\frac{\partial r^{*}}{\partial \delta}>0, \quad \frac{\partial R^{*}}{\partial \delta}<0, \quad \frac{\partial B^{*}}{\partial \delta}>0$
(iii) $\left.\frac{\partial r^{*}}{\partial M}\right|_{a=c \text { const }}<0,\left.\frac{\partial R^{*}}{\partial M}\right|_{a=\text { const }}>0,\left.\frac{\partial B^{*}}{\partial M}\right|_{a=\text { const }}>0$ 
The proof of Proposition 2 is included in the Appendix. As the search elasticity (indicated by $\mathrm{H}$ ) increases, the potential incentive cost of unemployment insurance grows, making it more desirable to rely on pension funded self-insurance; but the fact that insurance is more distortionary means that, in addition, the total unemployment benefit (tax funded plus pension funded self-insurance) decreases. Greater risk-aversion of a worker (a higher $\delta$ ) implies a greater need for insurance against the risk of unemployment, as well as greater reliance on tax-financed benefits more than pensionfunded self-insurance.

Consider some extreme cases. When a worker is risk-neutral, i.e., when $\delta=0, r^{*}=0$ : there is no need for unemployment insurance. Note from Proposition 1 (iii) that $R^{*}=1-s_{u}{ }^{*}$ in this case, which implies that the pension-funded self-insurance $\mathrm{R}$ takes care of all the necessary consumption smoothing for those with the work-state $\mathrm{U}$. Reliance on pension-funded self-insurance is also desirable when the reemployment probability of a worker is very sensitive to his search effort, i.e., when $\mathrm{H}$ is very large.

On the other hand, if a worker is very risk-averse ( $\delta$ is very large) or if his reemployment probability is constant irrespective of his search effort $(H=0)$, no pension-funded self-insurance will be necessary. In this case, $r^{*}=1$ by Proposition 1 (v), implying that after receiving the tax-funded benefit, which provides complete insurance so that it is equal to the wage the individual would have received had he been employed ${ }^{9}$, an unemployed worker saves some of the benefit so as to smooth out his consumption over time.

More importantly, Proposition 2 (iii) shows how the optimal benefit package for the unemployed changes with the length of working and retirement periods. The increase in 
$\mathrm{M}$ and $\mathrm{N}$ with $a$ kept constant indicates that the unemployment duration gets shorter relative to the length of working life. Under this circumstance the optimal benefit package for the unemployed entails a larger amount of pension-funded borrowing and a smaller amount of tax-funded benefit. The reason for this result is that the risk associated with unemployment viewed from a life-time perspective gets smaller, so that when it can be effectively smoothed as under the integrated UI system, the risk burden becomes negligible. That is, a worker who borrows from his pension can ease the burden of reduction in his lifetime income by spreading it out more effectively over the longer postunemployment and retirement periods, i.e., by increasing his savings during the postunemployment period and reducing his consumption during retirement.

\section{II.2. Government Intervention for the Second-Best Outcome : The Integrated UI System}

\section{II.2.1. The Relevance of Integration}

In this subsection we will see whether or not we need government intervention to support the second-best optimum we have described. There are two possible reasons for government intervention: first, all the second-best variables may not be decentralized by individual choices in competitive markets; and second, the second-best outcome may not be realizable under imperfect capital market as it involves individual borrowing against future income. 
Let us first look at the decentralization issue, assuming for the moment that the capital market is perfect. It is easy to verify that the second-best UI benefit $r^{*}$ can be supported as an equilibrium in a competitive insurance market. Since the government budget condition (7) is equivalent to the zero profit condition for an individual insurance firm, the maximization problem for $\mathrm{r}^{*}$ will be identical to the one for an equilibrium amount of insurance in a competitive market. ${ }^{10}$

In examining whether or not the other second-best variables - savings $\left\{s_{1}{ }^{*}, s_{n}{ }^{*}, s_{u}{ }^{*}\right\}$ and borrowings rate $R^{*}$ - can be decentralized by individual choices in a competitive capital market, we will presume that $\mathrm{r}=\mathrm{r}^{*}$. Let $\left\{s_{1}{ }^{i}, s_{n}{ }^{i}, s_{u}{ }^{i}, R^{i}\right\}$ be an individual's choices of savings and borrowings rates given $\left\{r^{*}, T^{*}\right\}$. An individual makes these choices by maximizing his expected utility (5) without the budget constraint (7) or without taking into account the effect of his search incentive on the UI tax (or premium) T. However, the equations (8) and (9) imply that both individual and second-best optimization problems for $s_{n}, s_{u}, R$ are the same, i.e., that if $r=r^{*}, s_{1}=s_{1}{ }^{*}$,

$$
s_{n}^{i}=s_{n}^{*}, s_{u}^{i}=s_{u}^{*}, R^{i}=R^{*}
$$

As for $\mathrm{s}_{1}{ }^{\mathrm{i}}$, on the other hand, it will be determined solely by intertemporal consumption smoothing because an individual takes $\mathrm{T}$ as given in choosing $\mathrm{s}_{1}{ }^{\mathrm{i}}$. Since this turns out to be the case for the optimal savings $s_{1}{ }^{*}$ by the assumption $(A), s_{1}{ }^{i}=s_{1}{ }^{*}$. Thus, we have established the following Proposition: 


\section{Proposition 3}

Under the assumption (A), the second-best outcome can be decentralized by individual choices in competitive markets, i.e.,

$$
s_{1}{ }^{i}=s_{1}{ }^{*}, s_{n}{ }^{i}=s_{n}{ }^{*}, s_{u}{ }^{i}=s_{u}^{*}, r^{i}=r^{*}, R^{i}=R^{*} \text {. }
$$

Conversely, if assumption $A$ is not satisfied, individuals in making their own savings decisions the first period fail to take into account the moral hazard effect associated with that savings. Hence, the greater the savings, the less the search intensity should they be unemployed, and accordingly the greater the burden on the unemployment insurance system. This is a standard externality-like effect that arises in insurance markets. In this case, it takes the somewhat surprising form that individuals will save too much. In this particular model, the government might be able to control the level of savings (assuming it is observable) by taxing savings that exceed $\mathrm{s}_{1} *$ at sufficiently high rates such that individuals will not save excessively. But more generally, the government will have to intervene to obtain a third best outcome by taxing activities that are substitutes for search and first period consumption and subsidizing activities that are complements. (See Greenwald and Stiglitz, 1986, and Arnott and Stiglitz, 1990) For the analytical simplicity we will not pursue these issues by assuming (A) in this paper.

Proposition 3 suggests that the government does not need to intervene if capital markets are perfect, so that individuals can borrow against future income. ${ }^{11}$ But because capital markets are not perfect, the government may have to intervene whenever an 
individual has to borrow to sustain his optimal consumption. Suppose that the government sets the mandatory savings rate in period 1 to be $\alpha s_{1}{ }^{*}$, where $\alpha \in[0,1]$. The amount of withdrawal an unemployed worker can make in period 2 would then be $(1-\alpha) s_{1}{ }^{*}$. Note that $\alpha$ would not affect any individual choice in this model so long as $\alpha \leq 1$, because $s_{1}{ }^{*}$ is the level of savings that an individual wants to make in period 1 . The amount of necessary borrowing for an unemployed individual will then be $\left(R^{*}-(1-\alpha) s_{1}{ }^{*}\right)$. Thus, the integrated UI system will be needed to support the secondbest optimum if the amount of borrowing required to sustain the second best optimum is positive, i.e., if

$$
(1-\alpha) s_{1}{ }^{*}<R^{*} \text {. }
$$

Condition (10) suggests that the integration of UI with a pension is likely to be relevant, or welfare enhancing ${ }^{12}$, when (i) the optimal borrowing $\mathrm{R}^{*}$ is large (which will be the case when the optimal tax-funded benefit $\mathrm{r}^{*}$ is small), (ii) the pre-unemployment savings is small, or (iii) the level of mandatory savings $(\alpha)$ is high.

Under certain circumstances an unemployed worker would not need to borrow much for his consumption. If the optimal pension-funded self-insurance $\mathrm{R}^{*}$ is small for the reasons presented above, for example, then the amount that an unemployed worker can withdraw $(1-\alpha) s_{1}{ }^{*}$ may be large enough to cover $\mathrm{R}^{*}$. In this case, the integration of UI with a pension would not be necessary. Furthermore, if the tax-funded benefit $r^{*}$ is very large, $\mathrm{R}^{*}$ may be non-positive, i.e., an unemployed worker may want to save out of the 
tax-funded benefit $\mathrm{r}^{*}$, in which case an integrated UI system would again not be relevant. However, we can present a certain set of parameter values for which integrated UI is always relevant. More specifically, Proposition 1, 2 and the condition (10) can give us some important results on the conditions for the relevance of integrated UI system. First, we can establish the following.

Proposition 4-1

For any given set of exogenous parameters $\{\alpha, q, H, \delta, N\}$, there exists $\bar{M}(<\infty)$ such that (10) holds if $M>\bar{M}=M(\alpha, q, H, \delta, N)$.

The proof is delegated to the Appendix. Proposition 4-1 demonstrates that an integrated UI system is desirable if $M$ (the post-unemployment working period) is long enough. The reason for this should be obvious: With a long working period (given a fixed retirement period), the savings rate required to finance retirement is lower. ${ }^{13}$ Also, long working period tends to render small the risk burden of self-insurance $\mathrm{R}$, leading to more self-insurance and less tax-funded benefit (by Proposition 3 (iii)). The reduction in $\mathrm{s}_{1}{ }^{*}$ and the increase in $\mathrm{R}^{*}$ imply the greater need for the integrated UI by (10). Note that integrated UI is relevant for large $\mathrm{M}$ because $\mathrm{s}_{1}{ }^{*} \rightarrow 0$ while $\mathrm{R}^{*}>0$ as M goes to infinity.

To examine other conditions for the relevance of the integrated UI, we will keep the ratio of employment duration to retirement duration, $a\left(\equiv \frac{M+2}{N}\right)$, constant, and will 
suppose that $a \geq 1$. Then, we can establish the following Proposition on the relevance of integrating UI with the pension program.

\section{Proposition 4-2}

Suppose that $a \geq 1$ and that $a$ is kept constant. There exists a set of finite parameter values $\left\{M^{o}, H^{o}, \delta^{o}\right\}$ for any given set of the other parameter values such that (10) holds if

(i) $M \geq M^{o}=M(\alpha, q, H, \delta, a)$,

(ii) $H>H^{o}=H(\alpha, q, M, \delta, a)$,

(iii) $\delta<\delta^{o}=\delta(\alpha, q, M, H, a)$.

The proof can be found in the Appendix. The result (i) shows that another feature of an individual career structure - the relative length of unemployment period - may also affect the relevance for an integrated UI. As both working and retirement periods get longer relative to unemployment duration, the pre-unemployment savings $\mathrm{s}_{1}{ }^{*}$ increases just a little due to the slight reduction in UI tax T (by Proposition 1 (i) and (v)) while the pension-funded self-insurance $\mathrm{R}^{*}$ increases (by Proposition 2 (iii)). Since the increase in $\mathrm{R}^{*}$ outweighs the increase in $\mathrm{s}_{1}{ }^{*}$, for large enough $\mathrm{M}($ and $\mathrm{N})$ integration becomes unambiguously desirable. This result can be seen another way: (10) will hold for large M and $\mathrm{N}$ because $s_{1}{ }^{*} \rightarrow \frac{1}{1+a}, R^{*} \rightarrow \frac{a}{1+a}$ as $\mathrm{M}$ and $\mathrm{N}$ go to infinity while $a>1$. 
Proposition 4-2 also shows that the integration of UI with a pension program would be necessary when workers are not so risk-averse and reemployment is relatively sensitive to search activity. When the economy is subject to serious incentive distortion, the taxfunded benefit decreases (by Proposition 1 (v)) and thus the need for borrowing grows (by Proposition 1 (iv)). The integration is necessary for large $\mathrm{H}$ because as $\mathrm{H}$ goes to infinity, all the consumption for the unemployed will be financed by self-insurance R (by Proposition 1 (iv) and (v)), which is greater than $\mathrm{s}_{1}$. If $\mathrm{H}=0$, i.e., if there is no incentive problem, there would be no need for pension-funded self-insurance, so that no integration might be necessary. If workers were risk-neutral, on the other hand, there would be no need for tax-funded benefits (by Proposition $1(\mathrm{v})$ ), implying the need for full integration. As workers become more risk-averse, however, the optimal tax-funded benefit would rise and thus need for integration would be reduced.

\section{II.2.2. Mandatory Savings}

It is obvious that the greater the level of mandatory savings, the greater the desirability of integration. More specifically, we can state the following Proposition, with its proof being delegated to the Appendix.

Proposition 4-3

$$
\frac{\partial \bar{M}}{\partial \alpha}<0,\left.\quad \frac{\partial M^{o}}{\partial \alpha}\right|_{a=\text { const }}<0, \quad \frac{\partial H^{o}}{\partial \alpha}<0, \quad \frac{\partial \delta^{o}}{\partial \alpha}>0 .
$$


As $\alpha$ approaches unity (all of first period savings are mandatory) then integration is always desirable so long as in the second best optimum, there is some pension-funded self-insurance, which there will be so long as individuals are not very risk averse and/or there is no moral hazard problem associated with search. This suggests that an economy with a strong public pension program should integrate unemployment insurance with the pension program.

In improving welfare relative to the conventional unemployment insurance, there might seem to be an alternative to integrating the public pension program with the unemployment insurance scheme: reducing $\alpha$ to zero or eliminating the public pension program. This is not the occasion to provide a full rationale for the existence of such programs. Our analysis is simply predicated on the observation that governments have chosen to provide such programs; if they do so, then our analysis has demonstrated that the unemployment insurance scheme should be integrated with it. But our analysis goes further: as we shall show in the next section, a program integrating unemployment insurance and pensions increases welfare relative to a purely private (non-mandatory) pension scheme, with imperfect capital markets, because it allows, in effect, for borrowing against future income.

While we do not provide here an analysis of the role of mandatory pension programs, we note that there are a number of factors which may make such schemes more or less attractive. For instance, societies in which there is more concern that elderly individuals do not fall below a certain threshold level—but in which at the same time there are many individuals willing to take advantage of society's compassion—will find it desirable to have at least a minimal mandatory program. ${ }^{14}$ If the incidence of 
unemployment is particularly high among those with low income-for whom the mandatory savings constitute a large fraction of their total savings - then integration will be desirable. In the United States, for instance, those at the bottom of the income distribution have little savings to which they can get access, and at the same time face higher risks of unemployment. Similarly, integration is likely to be of particular value in developing countries, where monitoring informal work may be difficult (so designing unemployment insurance schemes is more problematic) and where the poor both face high risks of unemployment and have low savings.

\section{II.3. Welfare Performance of the Integrated UI}

\section{II.3.1. Comparison Between the Conventional UI and Integrated UI}

We have stressed that the welfare advantage of an integrated UI system over the usual UI system arises from capital market imperfections. Without the government provision of pension-funded borrowings, when (10) holds, an unemployed worker would not only have to use savings made in period 1 in an effort to maintain the optimal consumption level, but he would have to undertake some additional (precautionary) savings in period 1 to supplement the tax-funded benefit $\mathrm{r}$ for his consumption while unemployed.

To present a clear comparison between the conventional UI system and the integrated system, we will assume that no mandatory savings is prescribed by the government, i.e.,

that $\alpha=0$. Suppose also that (10) holds, i.e., $s_{1}{ }^{*}<R^{*}$ so that integration is necessary for the second-best optimum. Then, we can show that the consumption level of an unemployed worker under the conventional UI system in the periods prior to the unemployment shock will be lower than the second-best level that can be achieved by the 
integrated system. Let $\hat{r}$ be the (tax-funded) UI benefit paid by the conventional UI system, and let $\hat{s}_{1}$ be the savings that an individual makes in period 1 under UI. Then we can prove the following results.

\section{Proposition 5}

Suppose that $\alpha=0$ and that $s_{1}{ }^{*}<R^{*}$. Then,

(i) $r^{*}<\hat{r}, R^{*}>\hat{s}_{1}$,

(ii) $r^{*}+R^{*}>\hat{r}+\hat{s}_{1}$.

The proof of the Proposition 5 is delegated to the Appendix. The Proposition confirms the earlier intuition: Under the conventional UI system, if a worker's optimal retirement savings $\mathrm{s}_{1}{ }^{*}$ in period 1 is not enough to replace the optimal pension-funded benefit $\mathrm{R}^{*}$, he would have to make additional savings in period 1 to ameliorate the consequences of the unemployment shock. Since this precautionary savings involves some efficiency costs, however, the savings made in period 1 would still be short of the optimal self-insurance $\mathrm{R}^{*}$ for the unemployed. Although the tax-funded benefit will increase to partially fill the gap, because of the costs associated with the distortion, it would be insufficient to secure the optimal consumption for the unemployed.

\section{II.3.2. Welfare Performance of the Integrated UI:}

\section{A Limiting First-Best Argument}


The welfare advantage of the integrated UI system stems from its ability to ease the risk burden caused by the insufficiency of (optimal) UI benefits by spreading out income loss over one's lifetime. In this subsection we will explore how much the integrated UI system can improve welfare. In particular, we will show that where the postunemployment working period $(\mathrm{M})$ or the retirement duration $(\mathrm{N})$ is very long, the integrated UI system can approximate the first-best optimum.

The condition (6) for the threshold search cost can be rewritten as

$$
\begin{aligned}
e^{*} & =(M+1+N)\left\{U\left(1-s_{n}{ }^{*}\right)-U\left(1-s_{u}^{*}\right)\right\} \\
& \approx(M+1+N)\left\{U^{\prime}\left(1-s_{u}{ }^{*}\right) X^{*}+U^{\prime \prime} \frac{X^{* 2}}{2}\right\} \\
& =\left(1-r^{*}\right) U^{\prime}\left(1-s_{u}{ }^{*}\right)+\frac{U^{\prime \prime}}{2}(M+1+N) X^{* 2}
\end{aligned}
$$

The payoff for a worker then under the optimal system $\left(r^{*}, R^{*}\right)$, denoted by $\mathrm{V}^{*}$, would be

$$
\begin{aligned}
V^{*}= & U\left(1-{s_{1}}^{*}-T^{*}\right)+(1-\bar{q}) I(.)+\bar{q} J(.)-q \int_{0}^{e^{*}} e d F \\
= & U\left(1-s_{1}{ }^{*}-T^{*}\right)+(M+1+N) U\left(1-{s_{n}}^{*}\right) \\
& -\bar{q}\left\{\left(1-r^{*}\right) U^{\prime}\left(1-s_{u}{ }^{*}\right)+\frac{U^{\prime \prime}}{2}(M+1+N) X^{* 2}\right\}-q \int_{0}^{e^{*}} e d F
\end{aligned}
$$

On the other hand, the first-best payoff for a worker, denoted by $\hat{V}$ as in (FB-3), will be 


$$
\begin{aligned}
\hat{V} & =(M+2+N) U(\hat{C})-\int_{0}^{\hat{e}} e d F \\
& =(M+2+N) U\left(C^{\prime}-\frac{\hat{q}}{M+2+N}\right)-\int_{0}^{\hat{e}} e d F \\
& \approx(M+2+N) U\left(C^{\prime}\right)-\hat{q} U^{\prime}\left(C^{\prime}\right)-\frac{(\hat{q})^{2}}{2(M+2+N)} U^{\prime \prime}-\int_{0}^{\hat{e}} e d F
\end{aligned}
$$

where $C^{\prime} \equiv \frac{M+2}{M+2+N}$ and $\hat{C}, \hat{q}$ are defined as in (FB-1) and (FB-2), respectively .

Then, we can now establish the following proposition:

\section{Proposition 6}

As $\mathrm{M} \rightarrow \infty$ while $\frac{M}{N}=a, r^{*} \rightarrow 0, \quad R^{*} \rightarrow \frac{a}{1+a}$, and the first-best state outcome, $\left\{\hat{C}=\frac{a}{1+a}, \hat{e}=U^{\prime}\left(\frac{a}{1+a}\right)\right\}$, can be approximated by the integrated UI system $\left(r^{*}, R^{*}\right)$.

The proof of Proposition 6 can be found in the Appendix. It highlights one of the several important aspects of an integrated UI system. As the period of postunemployment or retirement gets longer compared to the unemployment period, the integrated UI system makes arbitrarily small the amount of welfare distortion associated with pension-funded borrowings. This occurs because under the system the adverse risk effect becomes arbitrarily small, while maintaining the desired level of search incentives. In the limiting case, the pension-funded self-insurance would have no risk effect with no attenuation of incentives; there is a complete replacement of tax-funded benefit by 
pension-funded self-insurance. Full integration thus allows the achievement of the firstbest optimum.

As previously noted, if $a \geq 1$, then the integrated UI system will be relevant in approximating the first-best optimum. If $a<1$, however, the relevance of the integrated UI would depend upon the mandatory savings rate $\alpha$.

\section{4. Remarks}

\section{II.4.1. Multiple Unemployment Shocks and Participation Incentives}

We have dealt with, up to now, a simple case where an individual experiences only one unemployment shock in his career. In fact, however, people may experience several unemployment shocks, which are to be covered by the integrated UI system. We will briefly mention the effectiveness and benefit structure of the integrated UI system under this circumstance.

Replacing tax-funded benefit by pension-funded borrowing would still alleviate incentive cost associated with tax-funded benefit while reducing risk burden associated with borrowing. The benefit of the integrated UI system would be especially marked when the unemployment shocks occur earlier (rather than later) in one's career. Only if there is a risk of substantial correlation among the unemployment shocks, so there is a risk of substantial lifetime losses as a result of these shocks, do the benefits of integration become limited. Proposition 2 argued that if the unemployment shock was small relative to lifetime income (and if the unemployment shock came early in life) then integration was likely to be of particular value. Conversely, with multiple, highly correlated shocks, 
there is a risk that, in effect, the unemployment shock is large relative to lifetime, so that the gains from integration may be small.

The question then is whether or not total unemployment duration for an individual is short compared to his lifetime, which can be explored empirically. Feldstein and Altman (1998) demonstrated in a simulation study based on PSID that if an individual deposits a modest amount out of his income to his savings account to finance his unemployment benefit (that under the current UI system), the terminal balance of an individual savings account is positive for most of individuals. Similar studies by Vodopivec and Yun (2002) on developing countries such as Malaysia and Estonia reveal that for most individuals the amount of hypothetical lifetime unemployment benefit for an individual is only a small portion of lifetime savings . These results seem to support the relevance of an integrated UI system. $^{15}$

Intertemporal consumption smoothing implies that the optimal amount of borrowing (from one's pension) at a certain point in time is positively related to the level of his pension expected at that time. Thus, the integrated UI system may involve a different benefit mix for the unemployed depending upon their employment history. For an unemployed worker who has a relatively long period of unemployment experience and low level of expected pension savings in the future, for example, the amount of the desired borrowing (out of the pension program) will be small. These arguments suggest that the amount of borrowing offered to the unemployed by the integrated UI would decrease in the total duration of previous unemployment.

Another issue related to the relevance of integrated UI system relates to individual incentives to participate in the system, where such participation is voluntary. The 
participation incentive problem would be particularly prevalent among the young workers in the informal sector who are relatively more subject to unemployment risk than others

and who have yet to accumulate large pension savings. ${ }^{16}$ Once they have borrowed more than the entire balance in their individual accounts, they may desire to quit the system because of their repayment liabilities (if they are allowed to do so). This adverse incentive problem will clearly limit the amount of borrowing that the integrated UI can offer the unemployed in the informal sector. However, the concern about adverse effects on participation would not change the desirability of integration;. but instead changes the benefit mix offered by the system. In particular, it reinforces the argument given above that the optimal amount of borrowing for the young may be negatively related to the total duration of unemployment they have experienced. The detailed analysis regarding this issue will be left for future research.

\section{II.4.2. Myopic Behavior}

The integrated UI system enables an individual to self-insure himself against unemployment by using his pension and thereby maintaining his search incentive. The favorable incentive effect of self-insurance is thus based upon the presumption that an individual has the burden of repayment for the borrowing he makes during unemployment. Some may argue, however, that an individual worker is so myopic in reality that he may not act as if he has such a repayment burden, even when he does. In particular, especially for the young unemployed workers, the repayment of borrowing may be too remote to affect their search incentives; for such individuals, the impact on 
search of benefits financed through self-insurance is no different from that from government provided insurance.

For such individuals, search can only be affected by differences in income experienced in the short run; that is, only limitations on the total benefit $(r+R)$ will induce search.

In practice, even myopic individuals can respond to changes in consumption in the near term induced by success or failure in obtaining a job. Earlier, we noted that if an individual is not myopic, he will reduce his consumption (or increase his savings) after being reemployed in order to spread out the burden of borrowing, as indicated by the savings $\mathrm{s}_{\mathrm{n}}{ }^{*}$ and $\mathrm{s}_{\mathrm{u}}{ }^{*}$ characterized in Proposition 1. This implies that a rational individual in fact would start to pay for his borrowings just after a period of unemployment.

By the same account the government can mandate a myopic individual to save more for his retirement after experiencing unemployment. ${ }^{17}$ Thus our model suggests that the government can use this differential mandatory savings policy or experience-rated policy to help induce search. With myopic behavior, the government might need to impose a greater burden for repayment earlier in an individual's life in order to induce the second best level of search.

The welfare analysis of economies with myopic individuals is complicated by the difficulty of ascertaining the appropriate valuation function. Traditional economic analysis is concerned with individual's expected utility over their entire life. But with myopic individuals, there is no loss to the individual's expected utility (viewed at the beginning) to payments made out of retirement benefits to finance unemployment benefits. 


\section{II.4.3. Distributional Issue}

It has often been argued that the integrated UI system with individual accounts aggravates inequality among individuals. High-wage workers, who tend to get unemployed less frequently than low-wage workers, are able to accumulate more savings than under the tax-funded UI system. ${ }^{18}$ In response to this argument, we can raise the following two points.

First, there is another aspect of the integrated UI system that has a favorable implication for distribution. A key point of the integrated UI system is that it allows a worker to borrow against his future savings to finance a part of his unemployment benefit. This would be particularly beneficial to the low-wage workers who do not have much precautionary savings on their own against possible unemployment. Many studies have shown that income distribution among individuals at a particular point in time is more unequal than distribution of lifetime incomes. ${ }^{19}$ This implies that a young low-wage worker, who has a higher probability of becoming unemployed, has a high chance of moving up within the income strata of a society in the future. Thus it would be more beneficial to a low-wage worker than to a high-wage worker to use his future income to finance current consumption when he is unemployed.

Second, the government can provide an explicit subsidy to compensate for the implicit subsidy under the unintegrated system. Appropriately designed explicit subsidies can mimic the distributional impacts of the implicit subsidies, and would entail no incremental adverse incentive effects. 


\section{Toward a Joint Integration of Multiple Social Insurance Programs with Pension: An Integrated Lifetime Insurance}

We have argued that allowing a worker to withdraw from his pension to finance his consumption when faced with an unemployment shock can yield some welfare improvement. The idea of integration can be applied to other forms of social insurance than UI, such as health and disability insurance, that cover various shocks an individual may face in his life. We can then think of a comprehensive integration system that jointly integrates several social insurance programs with a pension program through an individual account. We refer to this as an integrated lifetime insurance system. If an individual experiences only a few shocks, so that the amount of corresponding income loss is small compared to his retirement savings, the previous argument for integration should still apply. Suppose, however, that an individual experiences so many of those shocks that were there heavy reliance on borrowing against future pension savings, his retirement account would be so drained that retirement consumption would fall below the socially acceptable level; there would have to be a government bailout. Since early in his life, the individual does not know what shocks await him in the future, there would seem to be a risk associated with any integration. Given this possibility associated with multirisk case, we will in this subsection briefly examine the relevance of a joint integration of social insurances with pension.

Before providing the more detailed arguments, we note that qualitatively there is an obvious answer to these concerns. The degree of integration —of borrowing against future pension income — can be state dependent. In effect, the amount of tax funded 
insurance provided against risks later in an individual's life depends on his cumulative experience. An individual with no experience of unemployment early in life will selfinsure against small health and disability risks later in life.

In general, the integrated lifetime insurance system consists of several social insurance programs integrated with the public pension program, providing an individual facing a particular shock with tax-funded benefit and pension-funded borrowing. As in the integrated UI, the benefit mix for a particular shock would depend not only upon riskaversion and incentive of an individual but also upon the parameters affecting the pattern of consumption smoothing. An important factor determining the benefit mix (the magnitude of the pension-funded borrowing) of an integrated social insurance is the amount of pension savings that is expected to be available at the time of retirement. If an individual under shock expects to have a relatively large amount of pension savings at the time of retirement, he would be offered a benefit mix consisting of large borrowings and a small tax-funded benefit.

There are a couple of reasons for the positive relationship between pension-funded borrowing offered by an integrated social insurance for an individual and his pension savings expected at the time of a shock. First, the greater amount of retirement savings for an individual implies that more borrowing is necessary for intertemporal consumption smoothing in the event of a shock. Second, lower expected pension savings for an individual implies a higher probability that the government bails him out to sustain a certain minimum level of retirement consumption. As the government bails out a low pension savings of an individual, the pension-funded borrowing to finance consumption in the face a shock would in fact have adverse disincentive effects. This is because the 
individual would know that his borrowing to sustain his consumption might not be repaid as he experiences more shocks in the future. In other words, the reason for reliance on pension-funded borrowing is to eliminate the adverse incentive effects of insurance; the possibility of a government bailout means that there is still some implicit insurance, and therefore there is still some adverse incentive effect. Note, however, that this adverse disincentive effect of borrowing is less severe than a tax-funded benefit to the extent that there is some probability that the borrowing is repaid.

The expected pension savings available to an individual at the time of retirement depends upon the amount of income loss caused by the shocks he experiences and the amount of borrowing under the integrated social insurances. Hence, the desired amount of pension-funded borrowing offered by an integrated social insurance for an individual will also be determined by two factors. ${ }^{20}$ First, the amount of borrowing for an individual under shock would be negatively related to the number and the sizes of other shocks that he has experienced in the past and is expected to go through in the future. If he has already experienced several shocks and borrowed substantially against his future pension, for example, he may not have been able to accumulate much savings for his retirement. This will lower his expected pension savings, implying that should he experience another shock, he should not rely much on pension-funded borrowing. If shocks are highly positively correlated with each other, the benefit mix of an integrated social insurance involves less self-insurance and more tax-funded benefits. Second, the level of integration for a particular social insurance program - the amount of pension-funded borrowing offered by an integrated social insurance against that particular risk—is constrained by the amount of pension-funded borrowing offered under other integrated 
social insurance programs. This is because a given amount of pension savings has to be shared for self-insurance against the shocks dealt with under several integrated social insurance programs.

This suggests that as more social insurance programs are integrated with the pension program, the level of integration for each will be lowered. This raises the question : Would it be relevant to integrate all the social insurance programs with the public pension scheme or to exclude some of them from the integration? The answer is that all the social insurances should be jointly integrated unless one risk is perfectly, positively correlated with another. With the risks being imperfectly correlated to each other, there is always some positive probability that an individual suffering from a shock later in his life has not experienced any other shock before, in which case some borrowing against his pension may be offered to him, and this will attenuate the adverse incentive effect of the taxfunded insurance program...

The basic idea behind the integrated lifetime insurance system is thus that there should be no constraint on the fund that confines its use to a specific set of shocks only. Such a constraint unambiguously lowers welfare. The joint integration allows us to have a common pool of pension savings that we can draw upon in funding benefit payments under different shocks. For those who have not experienced any shock and thus have not received benefits, for example, the system allows a relatively large amount of their pension savings to be used for the upcoming shocks (and retirement). Also, more pension savings can be used to finance the borrowing against an early shock if other subsequent shocks are expected to occur with a low probability before retirement.

The extent of welfare improvement from an integrated lifetime insurance would 
depend upon the correlation among the risks. If all the risks were perfectly, negatively correlated to each other, the joint integration would be able to give us the maximum welfare benefit by setting the highest possible level of integration for each social insurance. As the risks are more positively correlated to each other, the level of integration for each social insurance program that can be set by the joint integration system would become lower. When all the risks are perfectly correlated with each other, there is no advantage of sharing a common pool of savings, and hence no advantage in integration. Unless the risks are perfectly positively correlated, however, the integrated lifetime insurance system will always bring some welfare gain. ${ }^{21}$

These arguments for the integrated lifetime insurance system lend support to the Provident Fund in Singapore, Malaysia, and recently in Hong Kong. The Provident Fund, to which individuals contribute a portion of their wage earnings, covers several risks, such as disability, medical, and retirement risks. It should be noted, however, that there is an important difference between the Provident Fund and the integrated lifetime insurance introduced here: while the integrated lifetime insurance allows an individual to withdraw more than what he has contributed, the Provident Fund limits the amount of individual withdrawal to what he has accumulated in his account. Thus the levels of insurance and intertemporal consumption smoothing it can provide to individuals are considerably limited, compared to the integrated lifetime insurance system that allows them to access to future income.

\section{Conclusion}


The failure of markets to provide adequate insurance against certain risks has long been recognized. This, combined with the fact that social norms do not allow individuals in their old age to suffer from insufficient income, even when their misfortune arises partly because they have chosen to save insufficiently, provides a rationale for a public, compulsory pension program. This paper has developed a further advantage to the public, mandatory program; it allows for the collateralization of future wage income in a way which is not easily possible otherwise, thus allowing individuals to in effect self insure against a variety of risks.

This paper has addressed two related issues. The possibility of pension-funded selfinsurance does not eliminate the desirability of some tax-funded insurance, except under extreme circumstances. We have identified the factors on which the optimal degree of pension-funded self-insurance depends. Our analysis is consistent with the suggestion in the introduction of a heavy reliance on pension-funded self-insurance.

When there are multiple risks (including the risk of multiple bouts of unemployment), again some reliance on pension-funded self-insurance is in general desirable, unless the risks are perfectly correlated. The integrated lifetime insurance system can always generate a welfare gain from allowing a common pool of pension savings to be shared to finance the benefits for those facing various shocks. The general principle naturally leads to the suggestion of a fully integrated lifetime insurance system through a joint individual account, an extension of the Provident Fund of Singapore and Malaysia, ${ }^{22}$ where major risks including disability and health are integrated with the public pensions program.. 


\section{REFERENCES}

Arnott, Richard, B. Greenwald, and J. E. Stiglitz (1994), "Information and Economic Efficiency," Information Economics and Policy, 6(1), March, pp. 77-88.

Arnott, Richard, and J. E. Stiglitz (1990), "The Welfare Economics of Moral Hazard," in Risk Information and Insurance: Essays in the Memory of Karl H. Borch, H. Louberge (ed.), Norwell: Kluwer Academic Publishers, pp. 91-122.

Asher, M.G. (1994), Social Security in Malaysia and Singapore-practices, issues and directions, Institute of Strategic and International Studies, Malaysia, 1994.

Bjorklund, Anders (1993), “A Comparison between Actual Distributions of Annual and Lifetime Income: Sweden 1951-92,” Review of Income and Wealth, 39, pp. 377- 86.

Feldstein, Martin and Daniel Altman (1998), “Unemployment Insurance Savings Account," NBER Working Paper 6860.

Folster, S. and Trofimov, G. (1999), “Social Insurance based on Personal Savings Account: A Theoretical Analysis. Working Paper, The Swedish Research Institute of Trade, Stockholm.

Folster, S. (2000), “An Evaluation of Social Insurance Savings Account,” mimeo.

Greenwald, B, and J. E. Stiglitz (1986) "Externalities in Economies with Imperfect Information and Incomplete Markets," Quarterly Journal of Economics, May, pp. 229-264.

Orzag, M.J., Orzag, P.R., Snower, D.J., and Stiglitz, J.E. (1999), “ The Impact of Individual Accounts: Piecemal vs. Comprehensive Approaches”, Presented At the Annual Bank Conference on Development Economics, The World Bank.

OECD (1996), Employment Outlook, OECD, Paris. 
Stiglitz, J.E. (1993) "Perspectives on the Role of Government Risk-Bearing within the Financial Sector,” In Government Risk-bearing, M. Sniderman (ed.), Norwell, Mass.: Kluwer Academic Publishers, pp. 109-30.

Vodopivec, M. and Yun, J. (2002), “Unemployment Benefits Through Unemployment Savings Account," mimeo, The World Bank.

\section{APPENDIX}

\section{Proof of Lemma}

Given the choices of ${s_{n}}^{*},{s_{u}}^{*}, R^{*}$ in (8) and (9), we have

$$
\begin{aligned}
& \left(1-s_{n}{ }^{*}\right)=\frac{(M+1) s_{n}{ }^{*}+s_{1}}{N}=\frac{M+1+s_{1}}{N+M+1} \\
& r+R^{*}=1-s_{u}{ }^{*}=\frac{M s_{n}{ }^{*}+s_{1}-R^{*}}{N}=\frac{M+r+s_{1}}{N+M+1}
\end{aligned}
$$

Thus, differentiating (6) with respect to $r$ and $s_{1}$, we get the desired results from (8) and (9).

\section{Proofs of propositions:}

\section{$<$ Proposition 1 $>$}

The optimal choices of $\mathrm{s}_{\mathrm{n}}{ }^{*}, \mathrm{~s}_{\mathrm{u}}{ }^{*}, \mathrm{R}^{*}$ will imply by (8) and (9) that

$$
1-{s_{n}}^{*}=\frac{M+1+s_{1}^{*}}{N+M+1}
$$


$1-s_{u}{ }^{*}=\frac{M+r+s_{1}}{N+M+1}$.

Then, by assumption (A) and envelope theorem, the optimal savings $\mathrm{s}_{1}{ }^{*}$ will satisfy

$$
\begin{aligned}
\frac{d V}{d s_{1}} & =\frac{\partial V}{\partial s_{1}} \\
& =-U^{\prime}\left(1-s_{1}{ }^{*}-T\right)+(1-\bar{q}) U^{\prime}\left(\frac{M+1+s_{1}{ }^{*}}{N+M+1}\right)+\bar{q} U^{\prime}\left(\frac{M+r^{*}+s_{1}{ }^{*}}{N+M+1}\right) \\
& =0
\end{aligned}
$$

The condition (A3) leads to the result (iv) by the assumption (A). Substituting the result (iv) into (A1) and (A2), and using the assumption (A), we get the desired results (i) and (ii). Since $r^{*}+R^{*}=1-s_{u}{ }^{*}$ by (9), we have the desired result (iii) by (ii). Finally, the necessary condition for $\mathrm{r}_{1}{ }^{*}$ will be

$$
\begin{aligned}
& \bar{q}\left[U^{\prime}\left(\frac{M+r^{*}+s_{1}{ }^{*}}{N+M+1}\right)-U^{\prime}\left(1-s_{1}{ }^{*}-T^{*}\right)-U^{\prime}\left(1-s_{1}{ }^{*}-T^{*}\right) H r^{*} U^{\prime}\left(\frac{M+r^{*}+s_{1}{ }^{*}}{N+M+1}\right)\right] \\
& \quad=0
\end{aligned}
$$

Dividing both sides of (A4) by $U^{\prime}\left(\frac{M+r^{*}+s_{1}{ }^{*}}{N+M+1}\right)$ and using (A3) and the assumption (A), we can rewrite (A4) as the desired result (v).

\section{$<$ Proposition 2>}

(i) From Proposition 1 (v) we can see that $\frac{\partial r^{*}}{\partial H}<0$, implying that $\frac{\partial R^{*}}{\partial H}>0$ and $\frac{\partial B^{*}}{\partial H}<0$, by Proposition 1 (iii). 
(ii) From Proposition 1 (v) we can see that $\frac{\partial r^{*}}{\partial \delta}>0$, implying that $\frac{\partial R^{*}}{\partial \delta}<0$ and $\frac{\partial B^{*}}{\partial \delta}>0$, by

Proposition 1 (iii).

(iii) From Proposition $1(\mathrm{v})$ we can see that $\left.\frac{\partial r^{*}}{\partial M}\right|_{a=\text { const }}<0$, implying that $\left.\frac{\partial R^{*}}{\partial M}\right|_{a=c o n s t}>0$ by

Proposition 1 (iii) and (v). Solving for $X^{*}$ from Proposition 1 (v) and substituting it into (iii), we get the desired result that $\left.\frac{\partial B^{*}}{\partial M}\right|_{a=c o n s t}>0$.

\section{$<$ Proposition 4-1 >}

As $\mathrm{M} \rightarrow \infty, \mathrm{R}^{*} \rightarrow 1$ by Proposition 1 (iii) and (v). Also, $\mathrm{s}_{1}{ }^{*} \rightarrow 0$ by Proposition 1 (iv) because $\mathrm{r}^{*} \rightarrow 0$ as $\mathrm{M}$ $\rightarrow \infty$. This implies that (10) holds for large $\mathrm{M}$. When $\mathrm{M}=0$, on the other hand, $\mathrm{R}^{*}<0$ and $\mathrm{s}_{1}{ }^{*}>0$, implying that (10) does not hold when $\mathrm{M}=0$. These arguments establish the desired result.

\section{$<$ Proposition 4-2>}

(i) $\left.\frac{\partial R^{*}}{\partial M}\right|_{a=\text { const }}>0$ by Proposition 3 (iii). Also, $\left.\frac{\partial s_{1}^{*}}{\partial M}\right|_{a=c o n s t}=0$, because $\left.\frac{\partial T^{*}}{\partial M}\right|_{a=c o n s t} \approx 0$ by the $\operatorname{assumption}(\mathrm{A})$. Thus, $\left.\frac{\partial\left\{R^{*}-(1-\alpha){s_{1}}^{*}\right\}}{\partial M}\right|_{a=\text { const }}>0$.

$$
\text { As } \mathrm{M} \rightarrow \infty \text { with } a \text { being kept constant, } \mathrm{R}^{*} \rightarrow \frac{a}{1+a} \text { while } \mathrm{s}_{1}{ }^{*} \rightarrow \frac{1}{1+a} \text { by Proposition } 1 \text { (iii) and (iv) }
$$

because $^{*} \rightarrow 0$ by Proposition 1 (v). Since $a>1$, (10) will hold as $\mathrm{M} \rightarrow \infty$. When $\mathrm{M}=0$, (10) will not hold because $\mathrm{R}^{*}<0$ and $\mathrm{s}_{1}{ }^{*}>0$.

(ii) and (iii) 
$\frac{\partial r^{*}}{\partial H}>0$ (or $\left.\frac{\partial R^{*}}{\partial \delta}<0\right)$ by Proposition 3 (i) (or (ii)). Since $\frac{\partial s_{1}{ }^{*}}{\partial H}=0$ (or $\frac{\partial s_{1}{ }^{*}}{\partial \delta}=0$ ) because $\frac{\partial T^{*}}{\partial H} \approx 0$ (or $\frac{\partial T^{*}}{\partial \delta} \approx 0$ ) by the assumption (A). Thus, $\frac{\partial\left\{R^{*}-(1-\alpha) s_{1}^{*}\right\}}{\partial H}>0$ (or $\frac{\partial\left\{R^{*}-(1-\alpha) s_{1}^{*}\right\}}{\partial \delta}<0$ ). As $\mathrm{H} \rightarrow \infty($ or as $\delta \rightarrow 0), \mathrm{R}^{*} \rightarrow \frac{M+\frac{1}{1+a}}{N+M+1}$ while $_{1}{ }^{*} \rightarrow \frac{N}{N+M+2}$ by Proposition 1 (iii) and (iv) because $\mathrm{r}^{*} \rightarrow 0$ by Proposition 1 (v). Thus (10) will hold as $\mathrm{H} \rightarrow \infty$ (or as $\delta \rightarrow 0$ ). Similarly, as $\mathrm{H} \rightarrow 0$ (or as $\delta \rightarrow \infty), \mathrm{R}^{*} \rightarrow 0$ while $\mathrm{s}_{1}{ }^{*} \rightarrow \frac{N}{N+M+2}$, implying that (10) will not hold.

\section{<Proposition 4-3>}

Since $\alpha$ does not change $\mathrm{R}^{*}$ or $\mathrm{s}_{1}{ }^{*}, \frac{\partial\left\{R^{*}-(1-\alpha) s_{1}^{*}\right\}}{\partial \alpha}>0$, implying the desired results.

\section{$<$ Proposition 5>}

Let $\mathrm{s}_{1}(\mathrm{r})$ and $\mathrm{R}(\mathrm{r})$ satisfy

$$
\begin{aligned}
& -U^{\prime}\left(1-s_{1}(r)-t\right)+(1-\bar{q}) U^{\prime}\left((M+1) s_{n}{ }^{*}+s_{1}\right)+\bar{q} U^{\prime}\left(1-s_{u}{ }^{*}\right)=0, \\
& r+R(r)=1-s_{u}{ }^{*}
\end{aligned}
$$

for any given $r^{*}$. Also, let $s_{1}^{\prime}(r)$ be the precautionary savings of a worker who is not offered any pensionfunded borrowing by the government. Then, it satisfies

$$
\Omega\left(s_{1}{ }^{\prime}\right) \equiv-U^{\prime}\left(1-s_{1}{ }^{\prime}(r)-t\right)+(1-\bar{q}) U^{\prime}\left((M+1) s_{n}{ }^{*}+s_{1}{ }^{\prime}\right)+\bar{q} U^{\prime}\left(r+s_{1}{ }^{\prime}\right)=0
$$


Note that $\Omega(R(r))<0$, because $R(r)>s_{1}(r)$ and by the above condition for $\mathrm{s}_{1}(\mathrm{r})$. Thus,

$S_{1}{ }^{\prime}(r)<R(r)$, implying the desired result (i). The optimal tax-funded benefit $\mathrm{r}^{\prime}$ for a given precautionary savings $\mathrm{s}_{1}{ }^{\prime}$ should satisfy

$\bar{q}\left[U^{\prime}\left(r^{\prime}+s_{1}{ }^{\prime}\right)-U^{\prime}\left(1-s_{1}{ }^{-}-T^{\prime}\right)-U^{\prime}\left(1-s_{1}{ }^{\prime}-T^{\prime}\right) H r_{1} U^{\prime}\left(r+s_{1}{ }^{\prime}\right)\right]=0$.

Then, $-1<\frac{\partial r^{\prime}}{\partial s_{1}{ }^{\prime}}<0$, implying the desired result (ii).

\section{$<$ Proposition 6>}

$\mathrm{X} \rightarrow 0$ as $\mathrm{M} \rightarrow 0$ with $a$ being kept constant, implying that $r^{*} \rightarrow 0$ by Proposition $1(\mathrm{v})$, and that

$R^{*} \rightarrow \frac{a}{1+a}, s_{n}^{*}, s_{u}^{*} \rightarrow \frac{1}{1+a}$ by Proposition 1 (i), (ii), (iii). Since

$e^{*}=\{I()-.J().\} \rightarrow U^{\prime}\left(\frac{1}{1+a}\right)=\hat{e}$ as $\mathrm{M} \rightarrow \infty$ with $a$ being kept constant by (11), $\bar{q} \rightarrow \hat{q}$. Then,

by (12) and (13), $V^{*} \rightarrow \hat{V}$ as $\mathrm{M} \rightarrow \infty$. 


\section{FOOTNOTES}

* Department of Economics, Columbia University .Email: jes322@columbia.edu.

** Department of Economics, Ewha University, Seoul, Korea. Email: jyyun@ewha.ac.kr.

Financial support of the World Bank is gratefully acknowledged.

${ }^{1}$ See Orzag, Orzag, Snower and Stiglitz (1999) for a more general discussion. Folster and Trofimov (1999) also presented a theoretical analysis of individual savings account for social insurance.

${ }^{2}$ However, some detailed redistribution issues associated with the integration will be discussed later in this paper.

${ }^{3}$ Since in our model, there are no adverse selection problems.

${ }^{4}$ There are some reasons, including a moral hazard problem, why the government has to mandate individuals to make savings for pension. One of the reasons for a mandatory pension is that an individual may not save for retirement because they may expect the government to bail him out when he does not have savings at the time of retirement.

${ }^{5}$ Alternatively, we can model an individual as paying the UI tax whenever he is employed rather than in period 1 only. The difference in modeling would not affect the main results of this paper, however, so long as an individual can maintain his optimal consumption in each period for a given state by adjusting his savings or borrowings appropriately.

${ }^{6}$ This is also exactly the way an individual determines his savings $\mathrm{s}_{1}$, as will be shown later. In the more general case, savings in the first period does affect search intensity. Assume, for instance, that the individual lives only 6 periods, three work periods, three retirement periods, and faces unemployment in the second period. If, for some reason, he had no savings from the first period, failing to search in the second would reduce consumption per period in retirement by $50 \%$. On the other hand, if he had been very risk averse, had anticipated that he might be unemployed, and that he might be unlucky and face a high search costs, and so had set aside $60 \%$ of his income (so that he has complete smoothing in the worse case scenario), then the benefit to searching - the cost of not searching — is much less, and so the threshold e above which the individual does not search is much lower. 
${ }^{7} \mathrm{H}$ and $\delta$ are evaluated at the optimum. Assuming that the risk aversion $\delta$ and search elasticity $H$ are assumed to be constant for all consumption levels and $e^{\prime}$, respectively, we can see that the second-order condition for $\mathrm{r}^{*}$ is satisfied.

${ }^{8}$ Theoretically $\mathrm{R}^{*}$ could be negative as $\mathrm{r}^{*}$ becomes greater than one's optimal consumption level in period 2 , in which case a part of the tax-funded benefit has to be left for retirement consumption. Although this can be perceived as another type of integration between UI and pension, we will disregard this possibility in this paper.

${ }^{9}$ Remember that the wage has been normalized at unity.

${ }^{10}$ Note that all the individuals are of the same risk type in this model, so that insurance firms are not subject to adverse selection problems caused by privately-informed individual heterogeneity. Once we allow for individual heterogeneity, then the second-best UI benefit $\mathrm{r}^{*}$ for all types of individuals would not be supported as a competitive equilibrium.

11 There are, of course, other reasons that government intervention might be desirable. We focus here on problems of moral hazard. All insurance markets also face problems of adverse selection. In general, such markets are not constrained Pareto efficient. See Greenwald and Stiglitz [1986] and Arnott, Greenwald, and Stiglitz [1994]

12 This is because the second best optimum cannot be sustained without such integration.

${ }^{13}$ From Proposition 1 (i), the level of savings prior to the unemployment, $s_{1}$ is lowered.

${ }^{14}$ For a more extensive discussion of the role of government in risk bearing, see Stiglitz [1992]. The fact that mandatory pension savings cannot be withdrawn until retirement means that there is a considerable welfare burden placed upon individuals who may experience several shocks other than unemployment during their lifetime. These concerns may have placed some limits on the extent of mandatory savings. Integration may, accordingly, lead to still further welfare benefits (beyond those formally modeled in this paper: integration allows an increase in the level of mandatory savings, and thus an improvement in the quality of the safety net provided to the elderly.

${ }^{15}$ See also Folster (2000) for a simulation study on this issue based on Swedish data.

${ }^{16}$ A worker in the informal sector can effectively drop out of participation by not reporting income. This is assumed not to be possible in the formal sector. The concern is that the existence of large liabilities may 
induce individuals to move from the formal to the informal sector; there may be large costs associated with this distortion.

${ }^{17}$ In fact, our model already incorporates this type of mandatory savings: an individual is mandated to save the optimal level $\mathrm{s}_{\mathrm{u}}{ }^{*}$ after experiencing unemployment, which is greater than the optimal savings level $\mathrm{s}_{\mathrm{n}}{ }^{*}$ for those with no unemployment experience in period 2.

${ }^{18}$ In fact, in experience rated systems described before, the extent of redistribution through the UI system is limited.

${ }^{19}$ See Bjorklund (1993) and OECD (1996).

${ }^{20}$ This implies that the benefit mix offered by an integrated social insurance for an individual would also depend upon individual employment history as well as the nature of a shock he suffers from.

${ }^{21}$ There are some studies which indirectly suggest that shocks are not highly correlated for an individual during his lifetime: Bjorklund (1993) showed based upon Swedish data that lifetime income is more equally distributed among individuals than annual income. OECD (1996) also reported that the upward income mobility for low income individuals is higher than for high income individuals.

${ }^{22}$ For detailed information on the system, see Asher (1994). 







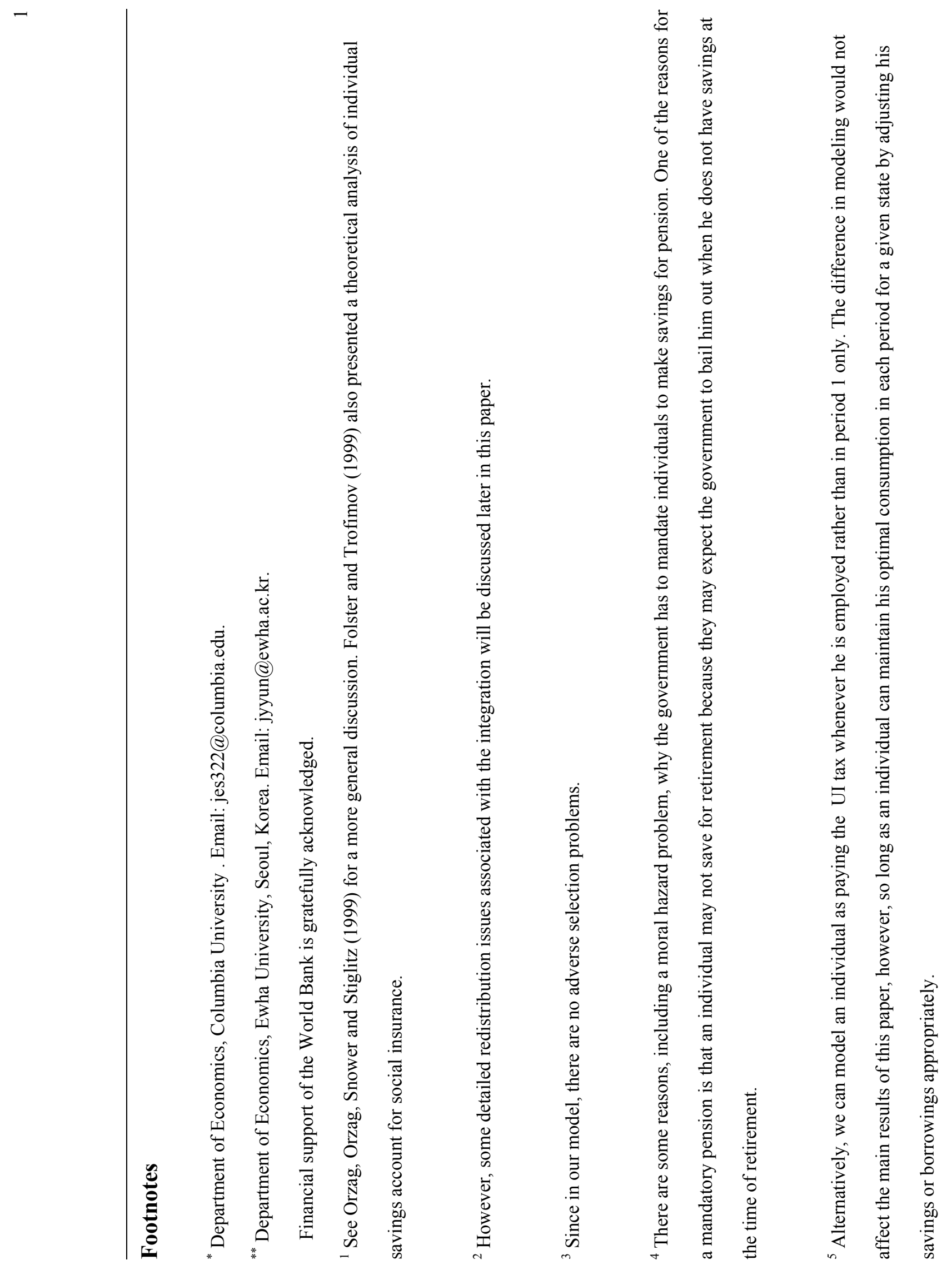




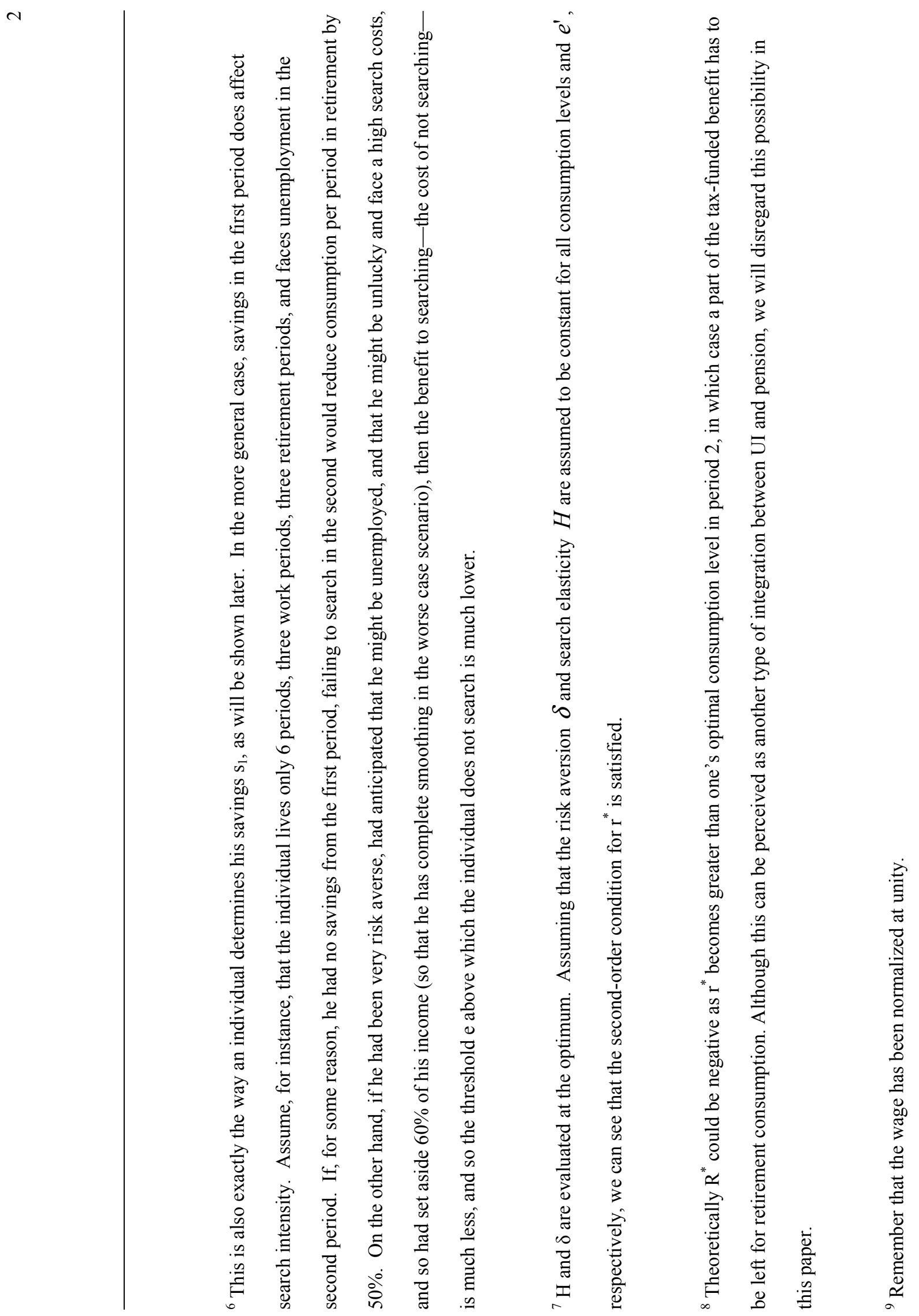




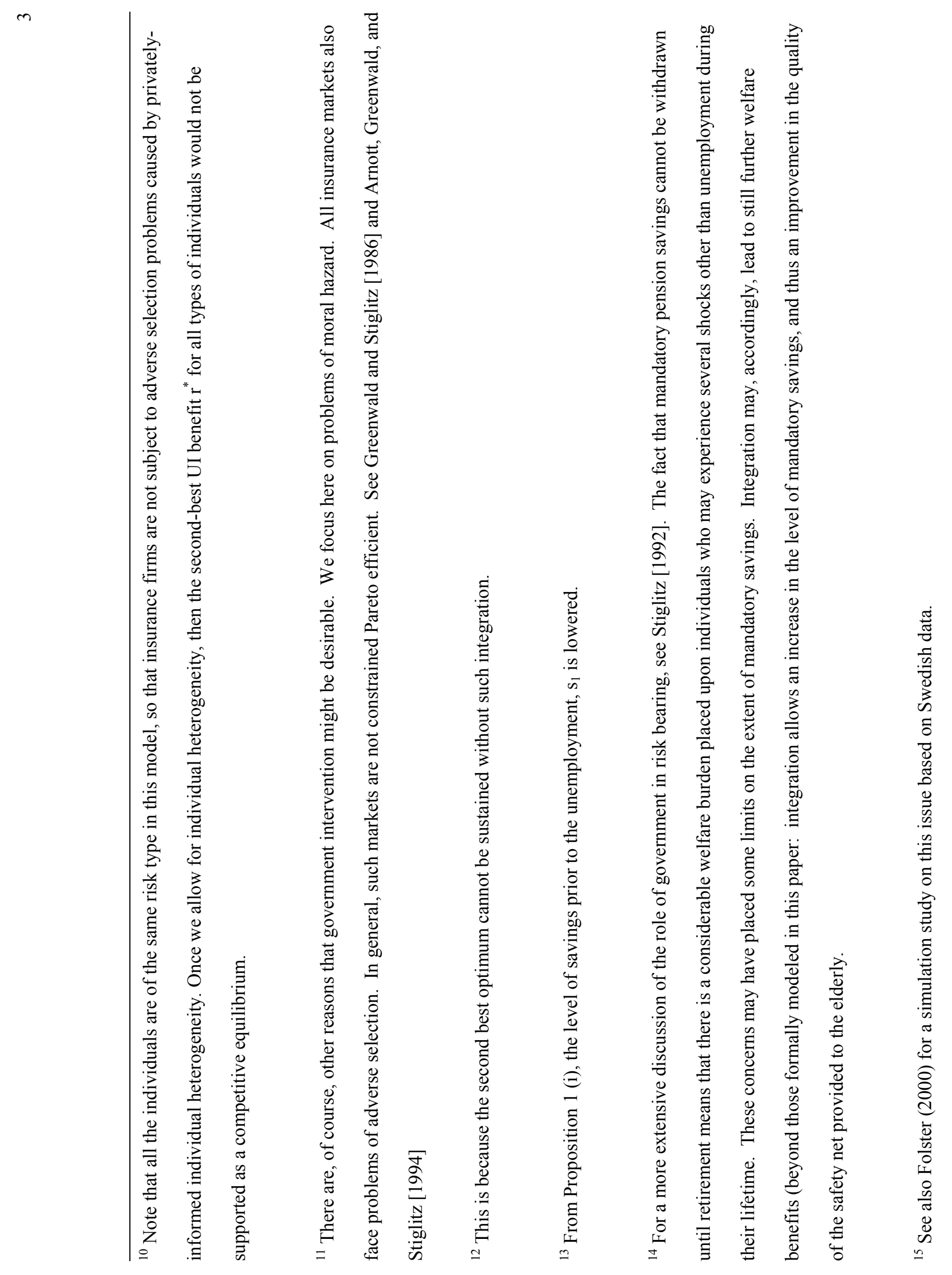




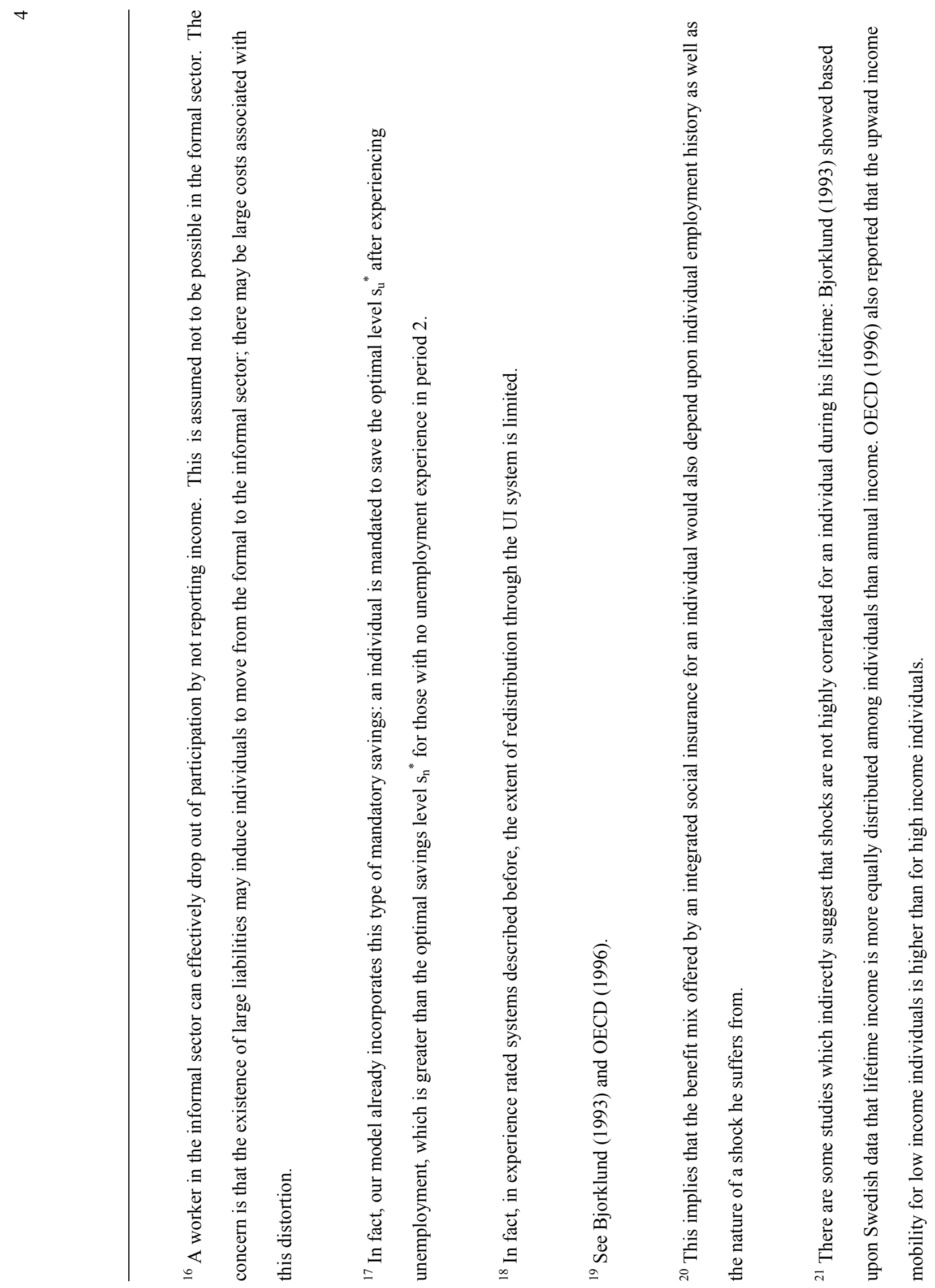




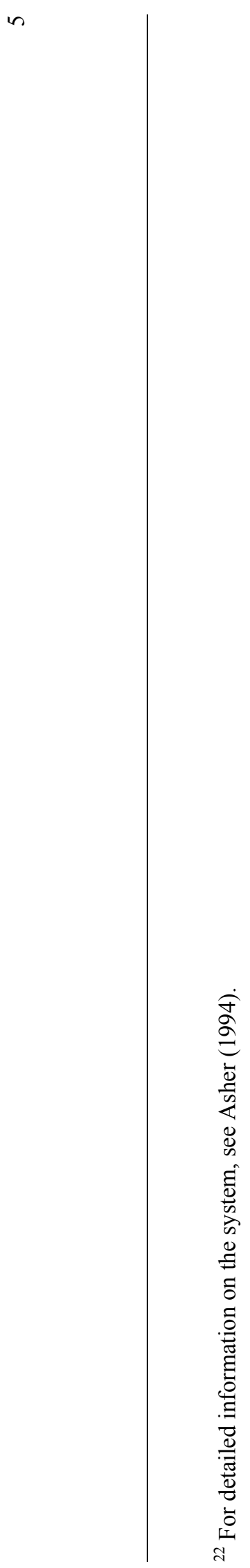

